\title{
19. Dilemmas of Engagement: Seriously empowering our community
}

\author{
Deb Symons
}

In my contribution to this volume I will analyse Victoria's approach to engaging with the communities affected by the 2009 'Black Saturday' bushfires. In the aftermath of the bushfires, the approach was taken to put communities at the centre of planning and decision-making, and to work extensively with them to develop recovery plans and to include their input into local government plans for the future.

Following the devastating bushfires in Victoria in February 2009, an unprecedented recovery effort was required and included the establishment of the Victoria Bushfire Reconstruction and Recovery Authority (VBRRA). The fires affected over 70 communities in diverse areas of Victoria and saw:

- over 2000 homes lost

- approximately 2000 homes seriously damaged

- a broad range of community infrastructure damaged or lost, including several schools and halls

- significant losses to business

- the loss of over 8000 livestock and an estimated 12,500 km of fencing

- the loss of an estimated 1,000,000 native animals

- most tragically, the loss of 173 lives.

\section{Approach to community engagement}

I joined the VBRRA in its first weeks and soon found myself managing the community engagement team, with community-led recovery as the central tenet of the organisation's recovery strategy.

It is important to stress the diversity of communities affected by the bushfires. While many people know of the suffering endured by communities such as Marysville and Kinglake, there were in fact over 70 communities across Victoria affected by the bushfires, with fire services responding to over 500 events in a single day.

The point of the above statistics is not to dwell on the detail of the fires and their impact but to highlight that our engagement, from the outset, had to recognise 
that the people we were to work with were devastated in so many aspects of their lives - be that through personal loss, loss of their home and security, loss of neighbours and friends, loss of income or employment, loss of livestock and long-held farming property, or loss of community.

Some areas were devastated. Moreover, they were often close to the urban fringe - Kinglake West is the most well-known example. The significance of this is that many people did not appreciate the risks inherent in the environment within which they lived, as they were so close to 'town'.

\section{Community led recovery}

A range of research tells us that communities recover best when they are enabled to participate and lead in their own recovery. Briefly, VBRRA's approach to the community-led recovery consisted of:

- VBRRA, in conjunction with many local government areas, supported the establishment of 33 Community Recovery Committees (CRCs) across Victoria.

- The members of each CRC were 'regular' community members, not organisation representatives.

- Each CRC was asked to prepare a community recovery plan with, and on behalf of, their community. They did this over several months, typically via workshops and planning days.

- In total, the 33 CRCs presented to government over 1100 recovery projects in their plans.

- A team of community engagement coordinators worked closely with CRCs and the wider community to engage, develop and nurture community participation and community confidence in undertaking their own local planning and decision-making.

As this was not the first such disaster experienced in Australia, a history of good practice, methodology and approach to recovery was available to be drawn on. The Victorian scenario, though, did have some unique elements to it, most notably the number of different communities affected. As a newly formed organisation, the VBRRA was also something of an unknown and none of the documented arrangements for state recovery included this entity; nonetheless the VBRRA was entrusted with coordinating and leading the recovery. To do this, it was necessary to work with all state government departments, several federal government departments, the Australian Defence Force and over 20 local governments. 
While CRCs were given only a single-line mention in the state's Emergency Management Manual, the VBRRA extended and formalised the concept and pushed for the formation of such committees across all of the communities affected by the bushfires. We also insisted that the CRCs be populated by 'regular' community members, despite many local governments initially preferring to fill them with representative of community groups, such as the Salvation Army and the Red Cross, who were assisting the bushfire recovery effort. It was evident that more direct engagement was necessary.

Each group formed in a different manner, based upon the characteristics of its community. Some communities held formal elections, others nominated people during a community meeting in the local hall, and others used local council support to call for nominations to form a committee.

The experience of the aftermath of the 'Black Saturday' bushfires reveals the dilemmas arising from attempts to seriously engage and empower communities. The following eight points encapsulate these dilemmas.

\section{Seriously empowering communities: A short list of complexities and dilemmas}

The greatest challenge of effective community engagement is that, put simply, it is the more difficult road to take. It requires:

- Senior and strong leadership backing this kind of approach is necessary for success.

- Leaders and policy-makers should be willing to have decisions that are not just supported by communities but also shaped by them. Be wary of false engagement strategies.

- Community members are not employees. As a group, they are unlikely to behave in a compliant or skilled fashion. Your skills as a facilitator, negotiator and arbitrator are critical.

- Engaging the community will lengthen the time required to make decisions. Other elements of your program need to recognise this.

- You can expect projects to cost more, not less, following community engagement.

- The community is likely to ask government to do 'non-governmental' things.

- Community engagement is not about efficiency. It is about the long-term health of communities, and recognition of the value of community spirit.

- In a world driven by Key Performance Indicators (KPIs), successful community engagement is hard to measure. 
1. I would suggest that with engagement if you do not have senior and strong leadership that 'gets it' and really 'wants it', then just don't do it. We were fortunate we had good leaders who sponsored engagement, became deeply involved in the process themselves and often intervened on decisions which had lacked engagement or were racing ahead without waiting for the community. There were plenty of people who did not support or agree with our approach, many of them senior leaders and decision-makers themselves. If we had not had the senior backing that we did with our approach, the whole thing would probably have been more damaging for communities than helpful, as it certainly raised expectations that required us to deliver upon regularly. Hence, engagement needs senior and strong leadership that understands and wants to engage with the community. This is essential for the success of such a program. Without the support of strong leadership in meeting the expectations of the communities, the VBRRA program would have been unsuccessful.

2. Engagement of this nature must inform and shape policy or service delivery decisions. Effective communication that allows communities to shape decisions is the basis of this form of engagement. While the VBRRA program received some eccentric and radical requests, on the whole the communities understood and expressed what they needed better than the administrators, and were happy to argue their point, negotiate their needs, and listen to the challenges faced in meeting their needs.

3. One of the challenges of engaging directly with community members is the diversity of individuals who find a voice as members of committees. Some of the people in the communities and on the CRCs were traumatised by the bushfires; some had trouble communicating; some could not remember the discussion and decisions of the week before. Many had never been involved in community committees or workshops or acted as representatives of their community, and they were not obliged to behave in a particular way. Community engagement does not always follow an orderly, well-paced, focused and necessarily respectful process. That said, I am proud of the lasting investment that we have made in these communities. Through the committees and ongoing activities and projects that were established, we can be certain that there is a much greater capacity and capability in these communities to form and run local committees now.

4. Related to the point above, but important as a distinct issue, it is critical to recognise that engaging with communities will almost certainly extend a project's timeline. Engagement is rarely something that can be done quickly, and it certainly is not something that can be rolled out towards the end of a program. People focused on community engagement have an important role 
in influencing others to ensure that the engagement strategy addresses the broad and specific aspects of the project, from the onset if possible.

5. Engagement will often result in greater costs rather than any cost savings, largely through an approach to negotiate with and learn from communities. The negotiation process might mean that government can deliver what it needs to, but it may have to add elements which assist the community, based on its preferences. For example, the VBRRA placed temporary health services in a number of communities; as we worked with communities and listened to them tell us what they needed, the range of services and the timeframes for which they were offered were extended. Thus, even though the visitation statistics did not highlight a need for the services, the communities convinced the VBRRA that this was due to lack of awareness of and comfort with these services, rather than lack of need for them. As a consequence, evening and weekend sessions on mental health first aid were held to make people feel comfortable about using the services.

6. The VBRRA was regularly asked to look into areas which did not fall within the purview of a government agency. The bushfire recovery process is an extreme case study, but communities came to see the VBRRA as a central coordinator for everything, not just for government services. As a result it became involved in events and projects outside its core business. The benefits of such engagement were clear: it built trust, rapport and respect necessary in the tense atmosphere in these ravaged communities. One example of this occurred in Marysville. After it became apparent that many of the landlords or owners along the main street were not in a position to re-establish their shops at the time, the community lobbied furiously for the government to buy one of the only standing buildings - a former car museum - and to fit out this building so that the supermarket could return. While governments are not usually in the business of purchasing commercial real estate, fitting it out for retail use and setting up a body corporate, in this instance such an approach was needed. It was a lengthy process - and the VBRRA was criticised by the community for not listening and for taking too long - but, in the end, their voices were heard and made a difference.

7. Engagement is not something that facilitates compliance responsibilities, nor does it drive efficiency.

8. It is not possible to consider the dilemmas of engagement without mentioning 'success'. Measuring the outcomes of engagement with communities is hard to do. It is important to define success for engagement activities early in the process, however, long-term evaluation is also crucial. There is also the issue of what defines 'value', not just for a particular project, but for community health more generally. Single department approaches are unable to adequately 
Putting Citizens First

account for this. Perhaps this is a challenge for the public sector to consider, as we are all contributing to community health in our own ways.

\section{Ongoing discussions and debates}

- Is there a genuine sponsorship of community engagement at the highest level of government?

- Are there tangible positive outcomes? How are they measured?

- Are we prepared to empower citizens or do we just want them to publicly agree with us? 